\title{
Introducing MyHouse Activity and MyWork Activity: A Paradigm Shift towards Lifestyle Physical Activity Supported by Evidence from a Focus Group Study
}

\author{
M. Felicia Cavallini ${ }^{1, *}$, Angela M. Kolen ${ }^{2}$, Xuemei Sui ${ }^{3}$, Lawrence L. Spriet ${ }^{4}$, Balkit King ${ }^{4}$, Emily Kraft $^{4}$, \\ Kurt Heischmidt ${ }^{3}$, Steven N. Blair ${ }^{3}$ \\ ${ }^{1}$ Limestone College, Department of Physical Education, Gaffney, South Carolina \\ ${ }^{2}$ St. Francis Xavier University, Department of Human Kinetics, Antigonish, Nova Scotia \\ ${ }^{3}$ University of South Carolina, Arnold School of Public Health, Columbia, South Carolina \\ ${ }^{4}$ University of Guelph, College of Biological Science, Guelph, Ontario \\ *Corresponding author
}

\begin{abstract}
The importance of exercise has long been substantiated as a means of preventing chronic diseases while improving quality of life. Most Canadians adults (85\%) do not obtain at least 150 minutes of moderate to vigorous physical activity each week, as advocated by the current Canadian PA guidelines. In physical activity promotional efforts, it may be important to consider a different perspective on which physical activities meet these guidelines. The purpose of this study was to examine people's beliefs, outlooks and attitudes towards physical activity and exercise. In phase I of this study, qualitative methods with phenomenological underpinnings were used. Facilitated group discussions were conducted with 234 adults from 13 diverse focus groups regarding their opinions, attitudes, outlooks, and beliefs on exercise versus physical activity. Using the transcriptions from phase I, a research-generated survey was designed by three content experts and administered to participants of the same community groups in phase II of the study to quantify feedback from phase I. Over 300 Canadian adults, ages 18 and older, provided questionnaire responses. More than $80 \%$ of the men and women preferred to meet their physical activity needs through household or lifestyle physical activities rather than structured or planned exercises. Furthermore, these men and women thought engaging in physical activity was a more natural, realistic and enjoyable part of their day than exercise. Additionally, most of these men and women think Canada's guidelines for physical activity can be achieved through physical activity alone. Given the overwhelming preference for lifestyle physical activities, emphasizing household and work activity, leisure, and active transportation as valuable methods to the current physical activity guidelines may be prudent.
\end{abstract}

Keywords: physical activity promotion, knowledge, attitudes, and behaviors, health promotion

Cite This Article: M. Felicia Cavallini, Angela M. Kolen, Xuemei Sui, Lawrence L. Spriet, Balkit Kang, Emily Kraft, Kurt Heischmidt, and Steven N. Blair, "Introducing MyHouse Activity and MyWork Activity: A Paradigm Shift towards Lifestyle Physical Activity Supported by Evidence from a Focus Group Study.” Journal of Physical Activity Research, vol. 6, no. 1 (2017): 61-67. doi: 10.12691/jpar-2-1-10.

\section{Introduction}

In spite of countless attempts to increase the physical activity (PA) level of the Canadian population, according to the Canadian Health Measures Survey, only 15\% of Canadian adults obtain the recommended 150 minutes of moderate-to-vigorous physical activity (MVPA) per week [1]. Although it is widely understood that regular exercise is fundamental to overall health and is one of the most beneficial intervention strategies for ameliorating various chronic conditions and numerous endeavors have been implemented, there has been little change in PA levels among Canadian adults [2,3,4].

Physical activity is defined by the Canadian Society for Exercise Physiology (CSEP) as any bodily movement that increases heart rate and breathing, and any movement produced by skeletal muscles that requires energy expenditure [5]. Moderate PA is defined as $50-60 \%$ of an individual's capacity. Vigorous activity involves $70-80 \%$ of an individual's maximal capacity. Exercise refers to the planned, continuous, and repetitive movements done with an intent to attain or maintain physical fitness.

Studies that addressed the topic of PA preferences indicate a preference for non-exercise PA versus exercise $[6,7,8]$. A substantial body of research shows health benefits resulting from lifestyle PA in each of the households (in and around the home) [9,10,11,12,13], leisure $[11,15,16,17]$, work-related [11,15-21], and active transportation-related [15,17,22,23,24,25] domains and many of the tasks performed in these areas reach the moderate intensity threshold defined above, in which many health benefits are realized. 
Our plan was to determine the challenges Canadians face towards meeting the recommended levels of PA in order to determine alternative methods of promoting higher levels of physical activity. Thus, the purpose of this study was to examine peoples' beliefs, outlooks, and attitudes towards PA and exercise. It was hypothesized that most participants would prefer lifestyle PA over traditional exercises.

\section{Material and Methods}

The primary objective of phase I of the study was to facilitate the sharing of individuals' perspective and personal experiences towards PA and exercise in their respective groups to better address the question: is the traditional means of exercising (typically thought of in a gym or fitness center) the best way to encourage people to become more physically active? We listened to the focus group members in hopes they would provide the depth of information that reflects the real challenges Canadians face in meeting the recommended levels of PA. In phase II of the study, the survey created using the feedback from phase I was administered to the same community groups.

\subsection{Participants}

Following research ethics board approval from the University of Guelph in November of 2014, the first phase of the study concentrated on the phenomenological, qualitative approach to gathering data. From December of 2014 to May of 2015, 1557 adults ages 18 years and up, representing 13 diverse groups from rural and urban communities in Southwestern Ontario, Canada were invited to participate in this study. More specifically, individuals representing diversity in gender, age, background, area of residence were invited including secondary school teachers, members of a rural parks and recreation department, Lion's Club members from a rural community, Mennonites, women's advocacy group, staff from the Guelph YMCA/YWCA, members from the Italian Canadian Club of Guelph, aqua participants from the Guelph YMCA/YWCA, Guelph Rotary Club, college students majoring in hospitality, food and tourism management, the Guelph Choir group, Hospice Wellington, and Wyndham House (an organization that supports young adults in a life without crime and addiction).

Each contact person from the 13 diverse focus groups received an e-mail with 3 attachments to distribute to each of their members in their respective groups. The first attachment was a letter of information prior to the focus group discussion which included both the inclusion and exclusion criteria. In order to participate in the study, the participant had to be: (1) 18 years of age or older, (2) a resident of either the City of Guelph or the Counties of Wellington and Dufferin, and (3) a member of one of the community groups in the study. The exclusion criteria were anyone with health conditions that precluded him or her from exercising. The second document highlighted sample discussion questions, and the third attachment was the informed consent, which contained the purpose, procedures, and importance of the study, potential risks and discomforts, benefits to participation and assurance of confidentiality.

\subsubsection{Procedure (Phase I)}

Focus group facilitated discussions were conducted with 234 people (15\% of the total potential sample. i.e., 234/1557). Ten of the thirteen focus groups included 6-12 participants and the other three were larger simply because of the type of group represented. Focus group interviews were held in the preferred meeting place for each group, i.e., Lion's Club for members of the Lion's Club, YMCA for staff members of the YMCA, etc. Efforts were made to create a comfortable atmosphere to facilitate a relaxed discussion; conversations were not recorded and each participant was reassured the discussions would be kept confidential.

At the beginning of each session, participants were asked to complete a short demographic questionnaire regarding their gender, age, and residence. The focus group discussions lasted approximately 30 to 60 minutes. These conversations were not recorded and participants were free to leave at any time without penalty. The same, trained investigator facilitated each focus group discussion following the same procedure. Guiding questions included: What do you think of when you hear the word exercise? What are your perceptions of PA? How many of you feel lack of time is one of the reasons why you're not active? So what does “you don't have time” mean? How many of you think lack of time is your biggest challenge? Probing questions followed and were dependent upon the participants' responses. Overall, the conversations were navigated to explore underlying factors for the overall lack of PA or exercise found in the Canadian adult population. Participants were urged to share their experiences and articulate their feelings regarding PA or exercise in this environment of minimum structure other than gentle probing questions to allow thoughts to flow freely and heighten the depth of detail within the group conversations.

These focus group discussions were observed by a small group of university students who made notes of the conversation as well as interpretations of what they heard. Upon completion of each focus group discussion, the students sent their typed notes to the group facilitator for a thorough review. In an effort to understand the perspectives and interpret the experiences of the participants, the data were analyzed through a phenomenological approach. In trying to understand and provide meaning to the explanations of the lived experiences relating to PA and exercise from the focus group participants, the notes were reviewed multiple times to allow essential ideas to emerge. This was an exhaustive process. The importance of the statements made by the participants were then deciphered into themes and categorized under separate headings and color-coded to arrange the data.

\subsubsection{Procedure (Phase II)}

Using the themes that emerged from the focus group interviews, a research generated survey was created to validate the findings of the focus group interviews. With this purpose in mind, common themes and trends that emerged from the focus group interviews were identified and analyzed by three content experts. These themes (agreed upon by all 3 specialists) were then used to construct a series of questions to reflect the responses from the focus group interviews. The newly created 
survey underwent several drafts before the final version materialized with unanimous support.

It became clear from the focus group data that many factors affected people's PA attitudes and behaviors. Among them, enjoyment, coupled with the perception that PA is more natural and easier to obtain within one's day, might motivate people to choose lifestyle or unstructured PA over exercise. Most participants noted that lifestyle PA was more positive, fun, and realistic to their everyday life than exercise.

Phase II of this study was approved by the research ethics board from the University of Guelph in July 2015. The newly formed surveys were then distributed from July 15 to September 30, 2015 to 323 individuals in the same community groups where the focus group data were collected. Following another letter of invitation, informed consents from these participants were obtained. Survey administration was scheduled at a convenient time and location suitable for each group with the objective of obtaining as many participants as possible. Participation in the focus group discussions was not required for completion of the survey. Basic demographic information (age, gender, place of residence) was collected again. Ninety-six percent (311/323) of the surveys distributed were completed providing valid questionnaire data for further analyses.

\subsection{Data Analysis}

Data analysis involved primarily descriptive statistics. Participants' responses to the survey were organized in Microsoft Excel, according to gender and in the following age groups: 18-34, 35-64, and 65 and up. Questions from the survey required "Yes" or "No" answers and were recorded accordingly ( 1 for "Yes" and 0 for "No"). The questions included:

1. Is there a difference between physical activity and exercise?

2. Do you think Canada's guidelines for physical activity can be achieved by physical activity alone?

3. Would you prefer to engage in more vigorous physical activity such as energetic yard work, brisk walking or forcefully raking leaves than exercise?

4. Do you think exercise is better for you than physical activity?

5. Is physical activity or exercise easier for you to do when it's goal-oriented (i.e. gardening) or when there's a destination/purpose (i.e. walking to work)?

6. When you are physically active, is it important to have one or more friends or colleagues to be physically active with?

7. Would you be interested in learning HOW to be more vigorously active in your everyday activities such as when walking the dog, shoveling snow or playing with your kids?

8. Is engaging in physical activity a more natural, realistic and enjoyable part of your day than exercise?

9. Is moderate to vigorous physical activity easier to incorporate into your day than exercise?

The total number of participants in each category (with respect to gender and age) was determined for each question.

\section{Results}

Table 1 indicates the number and percentage of survey respondents according to age and gender. Three hundred and eleven people completed the survey (63\% males) from either the 18-34, 35-64, or 65 and up group. Of the 1,557 individuals invited to participate in the focus groups, we invited 323 participants to complete the surveys. There was a very high response rate (96\%; 311/323) for the survey.

Table 1. The Number and Percentage of Survey Respondents According to Age and Gender

\begin{tabular}{|c|c|c|c|c|}
\hline & All ages & $\begin{array}{c}18-34 \\
\text { years }\end{array}$ & $\begin{array}{c}35-65 \\
\text { years }\end{array}$ & $\begin{array}{c}\text { Ages 65 years } \\
\text { and older }\end{array}$ \\
\hline $\begin{array}{c}\text { Number of } \\
\text { respondents }\end{array}$ & $\begin{array}{c}311 \\
(100 \%)^{\mathrm{a}} \\
(100 \%)^{\mathrm{b}}\end{array}$ & $\begin{array}{c}85 \\
(27 \%)^{\mathrm{b}}\end{array}$ & $\begin{array}{c}84 \\
(27 \%)^{\mathrm{b}}\end{array}$ & $\begin{array}{c}142 \\
(46 \%)^{\mathrm{b}}\end{array}$ \\
\hline Males & $\begin{array}{c}197 \\
(63 \%)^{\mathrm{a}}\end{array}$ & $\begin{array}{c}21 \\
(11 \%)^{\mathrm{a}}\end{array}$ & $\begin{array}{c}45 \\
(23 \%)^{\mathrm{a}}\end{array}$ & $\begin{array}{c}131 \\
(66 \%)^{\mathrm{a}}\end{array}$ \\
\hline Females & $\begin{array}{c}114 \\
(37 \%)^{\mathrm{a}}\end{array}$ & $\begin{array}{c}64 \\
(56 \%)^{\mathrm{a}}\end{array}$ & $\begin{array}{c}39 \\
(34 \%)^{\mathrm{a}}\end{array}$ & $\begin{array}{c}11 \\
(10 \%)^{\mathrm{a}}\end{array}$ \\
\hline
\end{tabular}

${ }^{\mathrm{a}}$ Percentage of respondents by gender

${ }^{\mathrm{b}}$ Percentage of respondents by age.

The results presented in Table 2 indicate convincingly that most participants across all age groups perceived a difference between PA and exercise (84\% males, 79\% females), and that engaging in PA is a more natural, realistic and enjoyable part of their day than exercise (82\% males, 80\% females). In addition, most participants think moderate to vigorous PA is easier to incorporate into their day than exercise (77\% males, $77 \%$ females) with $79 \%$ of the females from the $18-34$ age group and $84 \%$ of the males from the 35-64 age group representing the highest level of agreement. Overall, $77 \%$ of the males and $58 \%$ of the females thought that Canada's guidelines for PA can be achieved through PA alone. This question was supported especially by the males with agreement ranging from $71 \%$ (35-64 yrs) to $80 \%$ (18-34 yrs). Most male (68\%) and female $(60 \%)$ respondents indicated a preference to engage in more vigorous PA such as energetic yard work, brisk walking or forcefully raking leaves than exercise, with the greatest level of agreement in males and females in the 35-64 age range at 74\%. Moreover, $84 \%$ of males and $89 \%$ of females think PA or exercise is easier to do when it's goal-oriented (i.e. gardening) or when there's a destination or purpose involved (i.e. walking to work). Only $37 \%$ of males and $32 \%$ of females indicated exercise as better for them than lifestyle PA. Overall, more females (63\%) than males (49\%) indicated interest in learning how to be more vigorously active in everyday activities with the highest percentage in the youngest age category of 1834 years (62\% males, $74 \%$ females). Although overall, only $39 \%$ of males and $41 \%$ of females surveyed indicated that when physically active, it was important to have one or more friends or colleagues to be Canadians are meeting the recommended guidelines for PA to date, ${ }^{1}$ then acquiring the health benefits through unstructured or lifestyle PA has not been properly and proportionally promoted to parallel peoples' preferences for meeting the PA guidelines. Furthermore, if there is a widely held conviction that one can achieve 150 minutes of MVPA per 
week through leisure, active transportation and home and work responsibilities, then physical educators, exercise science specialists, health educators, kinesiologists, and other professionals in the fields of medicine and public health have an obligation to educate and inform the public in ways in which this can be done. physically active together with $71 \%$ of males and $48 \%$ of females in the 18-34 age group indicated a need for social support.

Table 2. The Percentage of Males and Females Who Responded "Yes" to the Question Posed

\begin{tabular}{|c|c|c|c|c|c|c|c|c|}
\hline Age & \multicolumn{2}{|c|}{ All ages } & \multicolumn{2}{|c|}{ Ages 18-34 } & \multicolumn{2}{|c|}{ Ages 35-64 } & \multicolumn{2}{|c|}{ Ages 65 and older } \\
\hline Gender & Male & Female & Male & Female & Male & Female & Male & Female \\
\hline Number of Respondents & $175-197$ & $101-114$ & $19-21$ & $58-64$ & $42-45$ & $35-39$ & $114-131$ & $8-11$ \\
\hline $\begin{array}{l}\text { Is there a difference between physical activity and } \\
\text { exercise? }\end{array}$ & 84 & 79 & 89 & 82 & 82 & 76 & 83 & 75 \\
\hline $\begin{array}{l}\text { Do you think Canada's guidelines for physical activity } \\
\text { can be achieved by physical activity alone? }\end{array}$ & 77 & 58 & 80 & 59 & 71 & 53 & 79 & 70 \\
\hline $\begin{array}{l}\text { Would you prefer to engage in more vigorous physical } \\
\text { activity such as energetic yard work, brisk walking or } \\
\text { forcefully raking leaves than exercise? }\end{array}$ & 68 & 60 & 45 & 46 & 74 & 74 & 69 & 91 \\
\hline $\begin{array}{l}\text { Do you think exercise is better for you than physical } \\
\text { activity? }\end{array}$ & 37 & 32 & 50 & 25 & 31 & 46 & 37 & 10 \\
\hline $\begin{array}{l}\text { Is physical activity or exercise easier for you to do when } \\
\text { it's goal-oriented (i.e. gardening) or when there's a } \\
\text { destination/purpose (i.e. walking to work)? }\end{array}$ & 84 & 89 & 81 & 88 & 84 & 92 & 85 & 89 \\
\hline $\begin{array}{l}\text { When you are physically active, is it important to have } \\
\text { one or more friends or colleagues to be physically active } \\
\text { with? }\end{array}$ & 39 & 41 & 71 & 48 & 34 & 33 & 35 & 27 \\
\hline $\begin{array}{l}\text { Would you be interested in learning HOW to be more } \\
\text { vigorously active in your everyday activities such as } \\
\text { when walking the dog, shoveling snow or playing with } \\
\text { your kids? }\end{array}$ & 49 & 63 & 62 & 74 & 44 & 50 & 48 & 45 \\
\hline $\begin{array}{l}\text { Is engaging in physical activity a more natural, realistic } \\
\text { and enjoyable part of your day than exercise? }\end{array}$ & 82 & 80 & 81 & 77 & 84 & 79 & 82 & 100 \\
\hline $\begin{array}{l}\text { Is moderate to vigorous physical activity easier to } \\
\text { incorporate into your day than exercise? }\end{array}$ & 77 & 77 & 62 & 79 & 84 & 69 & 77 & 100 \\
\hline
\end{tabular}

\section{MyHouse Activity}

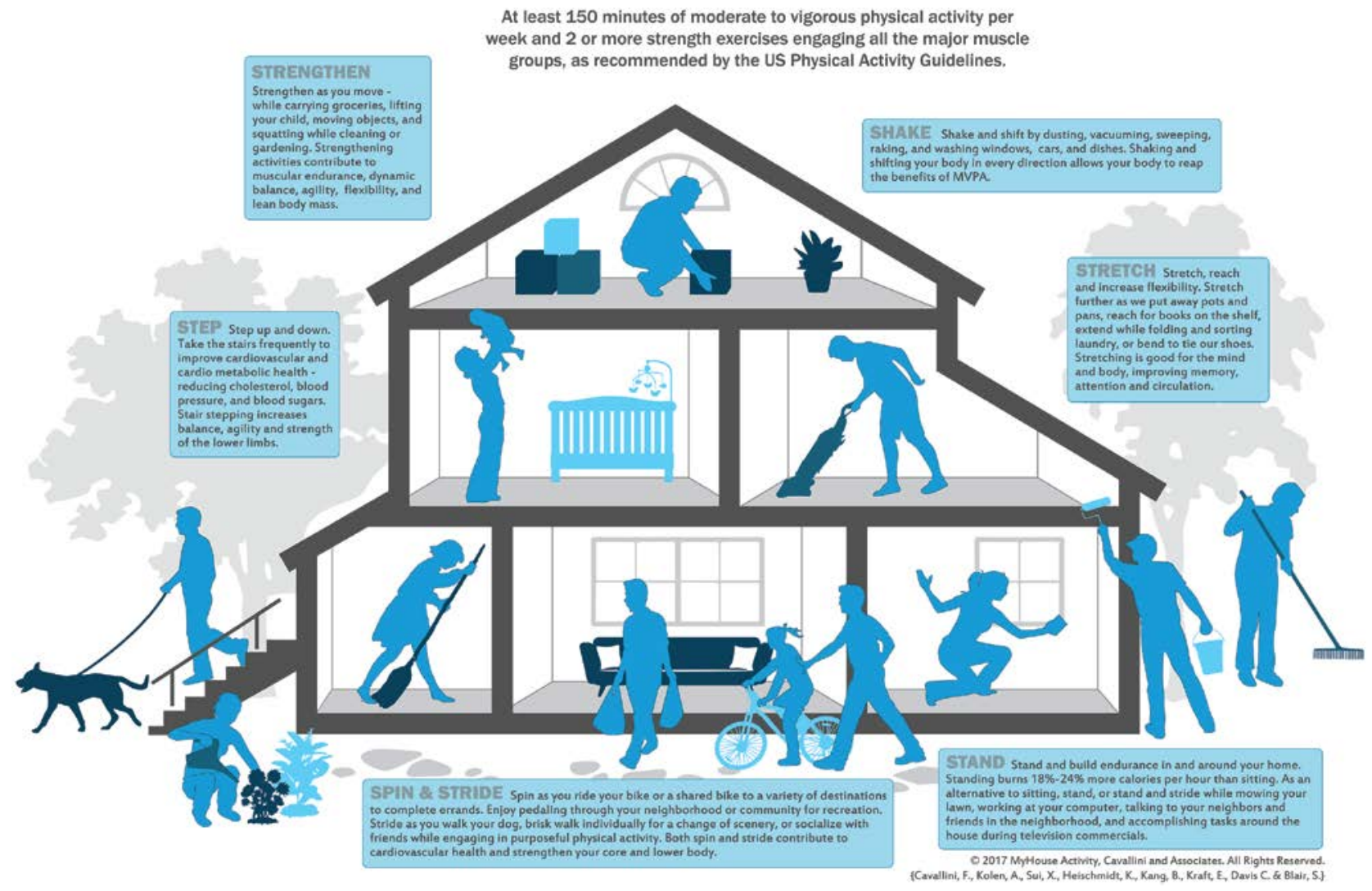

Figure 1. MyHouse Activity, Cavallini et al. All Rights Reserved. @2017 [26] 


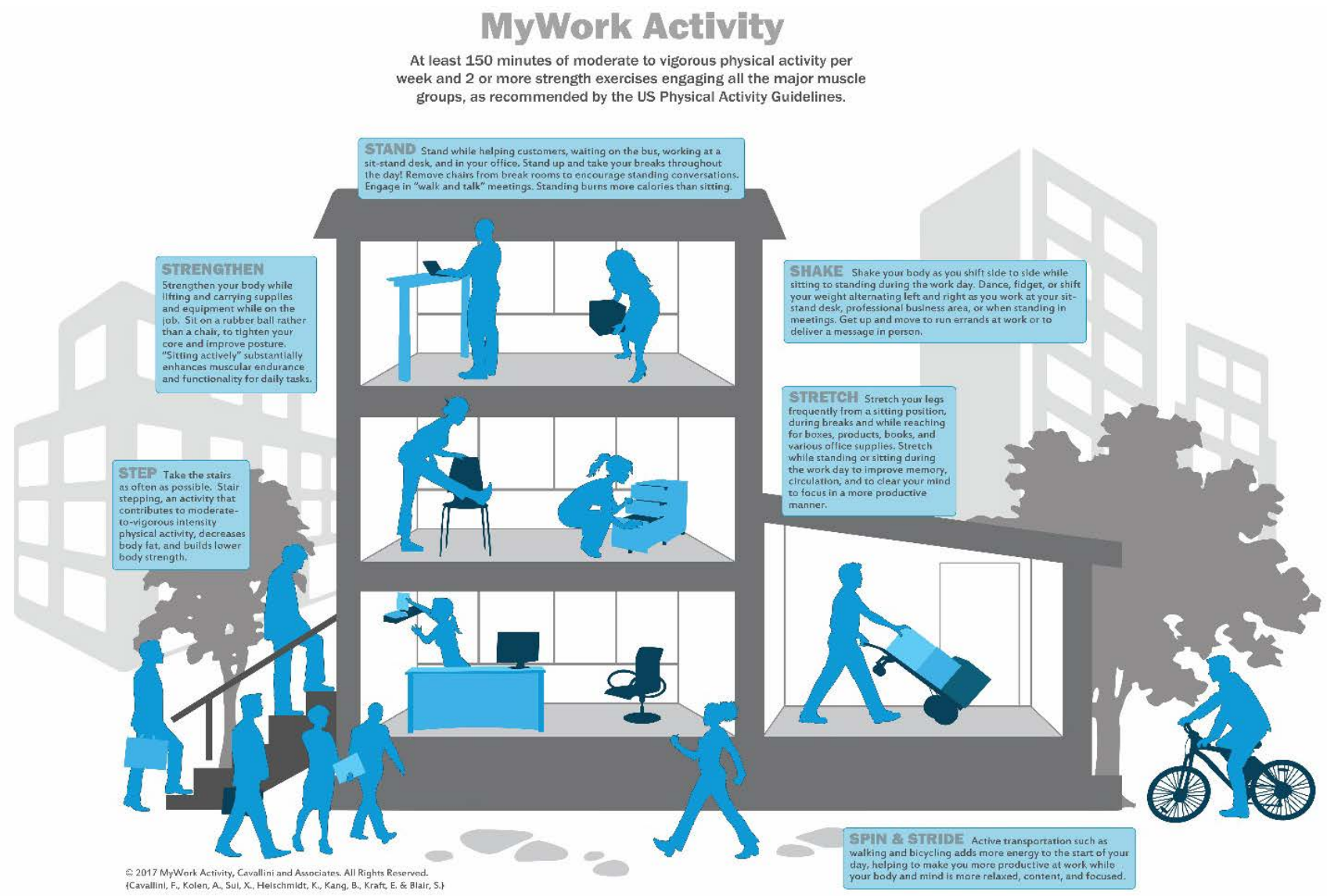

Figure 2. MyWork Activity, Cavallini et al. All Rights Reserved. (C2017 [27]

\section{Discussion}

With only $15 \%$ of Canadians meeting the minimal level of PA recommended [1] and most participants in this study indicating that 150 minutes of MVPA could be achieved through their everyday lifestyle activities, we need to rethink how we market, motivate, and inform the public to become more physically active. Taking into consideration the results from this study and others $[6,7,8]$ a major paradigm shift is critically important to the depiction of what exercise should look like and how to go about achieving PA in a more broad-minded approach to a healthier lifestyle. More PA images should reflect moderate to vigorous daily household tasks, everyday jobs, active transportation, errands, and work site responsibilities as demonstrated in Figure 1 and Figure 2.

\section{Conclusion}

The evidence collected from this study clearly suggests most people are not as interested in "working out" in a gym or engaging in the traditional forms of exercising such as jogging, "pumping iron," using the elliptical or other exercise machines. Rather, the results indicate a strong preference for making PA part of a daily lifestyle. If this is true, and we recognize that only $15 \%$ of Canadians are meeting the recommended guidelines for PA to date [1], then acquiring the health benefits through unstructured or lifestyle PA has not been properly and proportionally promoted to parallel peoples’ preferences for meeting the PA guidelines. Furthermore, if there is a widely held conviction that one can achieve 150 minutes of MVPA per week through leisure, active transportation and home and work responsibilities, then physical educators, exercise science specialists, health educators, kinesiologists, and other professionals in the fields of medicine and public health have an obligation to educate and inform the public in ways in which this can be done.

The few studies conducted in the areas of PA preferences point to the tendency for day to day lifestyle PA over exercise $[6,7,8]$. It may be that people engage in lifestyle PA for a broader range of reasons than those who exercise. Completing a task or performing useful work is often part of lifestyle PA and as a result, people may be more inclined to perform these kinds of PA than explicit exercise. This previous research was conducted with an Australian sample, so further research is needed to see whether these preferences are observed in other populations. Further, given the potential for non-exercise PA as an area of intervention to increase overall PA levels, an exploration of the connection between non-exercise physical activities or lifestyle PA is warranted.

Some contemporary interventions aimed at encouraging $\mathrm{PA}$ in the general population focus on inspiring people to move more energetically on a daily basis $[28,29,30]$ but the overwhelming number of exercise images, information and motivational strategies presented to the public do not reflect the strong degree of preference for every day PA among Canadians. The promotion of active living is evident in some materials, such as Canada's Guidelines for Physical Activity [5], but not to the degree the results from this study reveal about people's preference for movement. 
The responses of the participants surveyed in both phases of this study reinforce the concept that most people are more interested in engaging in physical activities such as household or yard work and find this method of acquiring PA easier and more doable, natural, and enjoyable to commit to than regular exercise across all age groups. For that reason, suggestions for obtaining the recommended PA guidelines should be more mainstreamed and concerted efforts should be made to address the public in a more realistic way to obtain PA as demonstrated in Figure 1 and Figure 2 for the at home and at work environments.

It should be noted that this study is limited by the self-report measures used as well as the imbalance of male and female participants overall and within each age group. Self-reported measures tend to have a higher potential for measurement error [31]. Because of the current PA status of Canadians, this study was specifically designed to ask PA and exercise questions to a wide range of focus group participants within the adult population to listen and gather comments and to consider emerging trends. There was no calculated effort to recruit the same number of participants for each age group or of male and females within each of the age groups. In spite of the skewed numbers representing the 65 and up participants (45\%) and two-thirds (67\%) of the participants identified an urban location as their place of residence, the results were consistent across all categories/age groups, which reflected convincingly, that males and females prefer to attain the recommended PA guidelines in everyday activity.

It is also possible that the use of convenience sampling regarding the focus groups may also have led to biased data. Using groups of participants who know and work closely to each other may produce weak injunctions due to that group's pre-existing dynamics [32]. This can pose a problem for analysis given the influence of relationships on contributions and the inhibition of negative observations [32]. Although the results of this study may be representative of the total population size of all the community groups, these conclusions are not generalizable across all populations, and therefore, not conclusive. It is necessary in future studies to sample more diverse ethnic populations, from a wider range of socio-economic status specific to age and gender with greater variance in population samples to validate and possibly standardized PA preferences.

\section{Acknowledgements}

This research study was funded by Fulbright United States and Fulbright Canada (2014-2015) and The College of Biological Sciences, University of Guelph (2015). A special thank you to Dr. Michael Emes, Former Dean of the College of Biological Science; Dr. Brian Husband, Associate Dean, Academic, College of Biological Science; Dr. Lawrence Spriet, Chair of the Human Health and Nutritional Sciences Department; Dr. Genevieve Newton, Associate Professor, Department of Human Health and Nutritional Sciences; Charlene Winchcombe-Forhan, Teaching and Laboratory Technician, College of Biological Science; Karen Armstrong, Health Promotion Specialist, Wellington-Dufferin-Guelph Public Health; Ishan Angra, Health Promotion Specialist, Healthy Communities Coordinator, Wellington-Dufferin-Guelph
Public Health; \& Karen Fradua, Health Promotion Specialist and Director, State of South Carolina.

\section{Competing Interests}

The authors have no competing interests to report.

\section{List of Abbreviations}

PA = Physical activity

MVPA = Moderate to vigorous intensity physical activity.

\section{References}

[1] Colley, R.C., Garriguet, D., Janssen, I., Craig, C., Clarke, J., and Tremblay, M.S. Physical activity of Canadian adults: Accelerometer results from the 2007-2009 Canadian Health Measures Survey. Health Reports 22(1):4-11. 2011.

[2] Shields, M., Tremblay, M.S., Laviolette, M., Craig, C.L. Janssen, I., and Conner Gorber, S. Fitness of Canadian adults: Results from the 2007-2009 Canadian Health Measures Survey. Health Reports 21(1):21-35. 2010.

[3] Physical Activity Guidelines Advisory Committee Report. Secretary of Health and Human Services, PsycEXTRA Dataset. 2008. Accessed July 20, 2017.

[4] Warburton, D.E.R., Charlesworth, S., Ivey, A., Nettlefold, L., and Bredin, S.S.D. A systematic review of the evidence for Canada's Physical Activity Guidelines for Adults. International Journal of Behavioral Nutrition and Physical Activity, 11; 7: 39. 2010.

[5] Canadian Society for Exercise Physiology (CSEP). Canadian Physical Activity Guidelines for Adults 18-64 years. Ottawa (ON): CSEP, www.csep.ca/CMFiles /Guidelines/CSEP-InfoSheetsadults-ENG.pdf. 2012. Accessed July 20, 2017.

[6] Booth, M.L., Bauman, A., Owen, N., and Gore, J.C. Physical activity preferences, preferred sources of assistance and perceived barriers to increased activity among physically inactive Australians. Preventive Medicine, 26: 131-137. 1997.

[7] Burton, N.W., Khan, A., and Brown, W.J. How, where and with whom? Physical activity context preferences of three adult groups at risk of inactivity. British Journal of Sports Medicine, 46(16): 1125-1131. 2012.

[8] Salmon, J., Owen, N., Crawford, D., Bauman, A., and Sallis, J.F. Physical activity and sedentary behavior: A population-based study of barriers, enjoyment, and preference. Health Psychology, 22(2): 178-188. 2003.

[9] Ainsworth, B.E., Haskell, W.L., Herrmann, S.D., Meckes, N., Bassett Jr, D.R., Tudor-Locke, C., et al., Compendium of Physical Activities: A second update of codes and MET values. Medicine and Science in Sports and Exercise, 43(8): 1575-1581. 2011.

[10] Besson, H., Ekelund, U., Brage, S., Luben, R., Bingham, S., Khaw, K., and Wareham, N.J. Relationship between subdomains of total physical activity and mortality. Medicine and Science in Sports and Exercise, 40(11): 1909-1915. 2008.

[11] Huerta, J.M., Chirlaque, M.D., Tormo, M.J., Buckland, G., Ardanaz, E., Arriola, L., et al. Work, household, and leisure-time physical activity and risk of mortality in the EPIC-Spain cohort. Preventive Medicine, 85: 106-112. 2016.

[12] Lawlor, D., Taylor, M., Bedford, C., and Ebrahim, S. Is housework good for health? Levels of physical activity and factors associated with activity in elderly women. Journal of Epidemiology and Community Health, 56(6): 473-478. 2002.

[13] Samitz, G., Egger, M., and Zwahlen, M. Domains of physical activity and all-cause mortality: Systematic review and doseresponse meta-analysis of cohort studies. International Journal of Epidemiology, 40(5): 1382-1400. 2011.

[14] Stamatakis, E., Hamer, M., and Lawlor, D.A. Physical activity, mortality, and cardiovascular disease: Is domestic physical activity beneficial? The Scottish Health Survey-1995, 1998, and 2003. American Journal of Epidemiology, 15; 169(10): 1191-1200. 2009. 
[15] Andersen, L.B., Schnohr, P., Schroll, M., and Hein, H.O. Allcause mortality associated with physical activity during leisure time, work, sports, and cycling to work. Archives of Internal Medicine, 160(11): 1621-1628. 2000.

[16] Hotelman, A., Marott, J.L., Gyntelberg, F., Søgaard, K., Suadicani, P., Mortensen, O.S., et al. Occupational and leisure time physical activity: Risk of all-cause mortality and myocardial infarction in the Copenhagen City Heart Study. A prospective cohort study. British Medical Journal, 2(1): e000556. 2012.

[17] Hu, G., Jousilahti, P., Borodulin, K., Barengo, N.C., Lakka, T.A., Nissinen, A., et al. Occupational, commuting and leisure-time physical activity in relation to coronary heart disease among middle-aged Finnish men and women. Atherosclerosis, 194(2): 490-497. 2007.

[18] Blair, S.N. A public health intervention model for work-site health promotion. Impact on exercise and physical fitness in a health promotion plan after 24 months. Journal of the American Medical Association, 255(7): 921-926. 1986

[19] Krause, N., Brand, R.J., Arah, O.A., and Kauhanen, J. Occupational physical activity and 20-year incidence of acute myocardial infarction. Scandinavian Journal of Work and Environmental Health, 41(2): 124-139. 2014.

[20] Morris, J., Heady, J., Raffle, P., Roberts, C., and Parks, J. Coronary heart-disease and physical activity of work. Lancet, 262(6795): 1053-1057. 1953

[21] Paffenbarger, R.S. and Hale, WeE. Work activity and coronary heart mortality. New England Journal of Medicine, 292(11): 545-550. 1975.

[22] Hamer, M. and Chida, Y. Active commuting and cardiovascular risk: A meta-analytic review. Preventive Medicine, 46(1): 9-13. 2008.
[23] Larouche, R., Faulkner, G., and Tremblay, M. Active travel and adults' health: The 2007-to-2011 Canadian Health Measures Surveys. Health Reports, 27(4); 10-18. 2016.

[24] Matthews, C.E., Jurj, A.L., Shu, X., Li, H., Yang, G., Li. Q., and Zheng, W. Influence of exercise, walking, cycling, and overall non-exercise physical activity on mortality in Chinese women. American Journal of Epidemiology, 165(12): 1343-1350. 2007.

[25] Mueller, N., Rojas-Rueda, D., Cole-Hunter, T., Nazelle, A.D., Dons, E., Gerike, R., et al. Health impact assessment of active transportation: A systematic review. Preventive Medicine, 76: 103-114. 2015.

[26] Cavallini, M. F., Kolen, A.M., Sui, X., Heischmidt, K., Kang, B., Kraft, E., Davis, C. \& Blair, S. MyHouse Activity, Cavallini and Associates. All Rights Reserved. (c) 2017.

[27] Cavallini, M. F., Kolen, A.M., Sui, X., Heischmidt, K., Kang, B., Kraft, E. \& Blair, S. MyWork Activity, Cavallini and Associates. All Rights Reserved. (C) 2017.

[28] Healthy Living Program. Public Health Agency of Canada, www.publichealth.gc.ca. 2014. Accessed July 20, 2017.

[29] Mobilizing Knowledge on Active Transportation. Public Health Agency of Canada, www.publichealth.gc.ca. 2015. Accessed July 20, 2017.

[30] National Complete Streets Coalition. Smart Growth America. www.smartgrowthamerica.org/complete-streets. 2016. Accessed July 20, 2017.

[31] Sallis, J.F., Hovell, M.F., Hofstetter, C.R., Faucher, P., Elder, J.P., Blanchard, K., et al. A multivariate study of determinants of vigorous exercise in a community sample. Preventive Medicine, 18: 20-34. 1989.

[32] Freeman, T. "Best Practice" in focus group research: making sense of different views. Journal of Advanced Nursing, 56 (5): 491-497. 2006. 